\title{
Papers
}

\section{Effectiveness of anticholinergic drugs compared with placebo in the treatment of overactive bladder: systematic review}

Peter Herbison, Jean Hay-Smith, Gaye Ellis, Kate Moore

\begin{abstract}
Objective To determine the effectiveness of anticholinergic drugs for the treatment of overactive bladder syndrome.

Design Systematic review of randomised controlled trials.

Data sources Published papers and abstracts. Study selection Randomised controlled trials with anticholinergic drug treatment in one arm and placebo in another.

Data extraction Primary outcomes of interest were patient perceived cure or improvement in symptoms, differences in number of incontinent episodes and number of voids in 24 hours, and side effects. Secondary outcomes of interest were urodynamic measures of bladder function (volume at first contraction, maximum cystometric capacity, and residual volume) and adverse events.
\end{abstract}

Data synthesis 32 trials were included, totalling 6800 participants. Most trials were described as double blind but were variable in other aspects of quality. At the end of treatment, cure or improvement (relative risk $1.41,95 \%$ confidence interval 1.29 to 1.54 ), differences in incontinent episodes in 24 hours (estimated mean difference $0.6,0.4$ to 0.8 ), number of voids in 24 hours $(0.6,0.4$ to 0.8$)$, maximum cystometric capacity ( $54 \mathrm{ml}, 43 \mathrm{ml}$ to $66 \mathrm{ml})$, and volume at first contraction (52 ml, $37 \mathrm{ml}$ to $67 \mathrm{ml})$, were significantly in favour of anticholinergics $(\mathrm{P}<0.0001$ for all $)$. Anticholinergics were associated with significantly higher residual volumes $(4 \mathrm{ml}, 1 \mathrm{ml}$ to $7 \mathrm{ml} ; \mathrm{P}=0.02)$ and an increased rate of dry mouth (relative risk 2.56, 2.24 to $2.92 ; \mathrm{P}<0.0001$ ). Sensitivity analysis, although affected by small numbers of studies, showed little likelihood of an effect of age, sex, diagnosis, or choice of drug.

Conclusions Although statistically significant, the differences between anticholinergic drugs and placebo were small, apart from the increased rate of dry mouth in patients receiving active treatment. For many of the outcomes studied, the observed difference between anticholinergics and placebo may be of questionable clinical significance. None of these studies provided data on long term outcome.

\section{Introduction}

Symptoms of overactive bladder comprise urgency (sudden and compelling desire to pass urine, which is difficult to defer), urge urinary incontinence (involuntary leakage of urine with the feeling of urgency), and frequency (voiding more than seven times a day), or nocturia (waking to void more than once at night). Urodynamic manifestations include a reduced maximum cystometric capacity (the bladder volume at which the person feels they can no longer delay micturition) and detrusor contractions that cannot be voluntarily inhibited. If a relevant neurological condition coexists then the term neurogenic detrusor overactivity is used, otherwise the disorder is called idiopathic detrusor overactivity.

Symptoms of an overactive bladder are common in adults in the community. Around one sixth of both 16776 randomly selected adults aged 40 years or over in six European countries and 5204 adults aged 18 years and over in the United States reported symptoms of an overactive bladder. ${ }^{12}$ One third of people with overactive bladder have urge urinary incontinence. Several large population studies have reported that the prevalence of symptoms of overactive bladder increases with age. ${ }^{1-5}$ In people with neurological conditions, such as multiple sclerosis, urinary dysfunction seems to be more common than in people who are neurologically unimpaired. ${ }^{6}$

Frequency and urgency can be just as bothersome as leakage, and overall the effects of overactive bladder symptoms on quality of life are profound. ${ }^{17}$ Many affected people do not seek help from professionals. ${ }^{15}$

The two main treatment options for overactive bladder syndrome are bladder retraining and anticholinergic drugs. By blocking the parasympathetic pathway anticholinergics abolish or reduce the severity of detrusor muscle contraction. None of the currently available drugs selectively targets the $M_{2}$ or $M_{3}$ muscarinic receptors of the bladder. As a result the drugs often cause side effects by affecting muscarinic receptors elsewhere, resulting in dry mouth or eyes, constipation, and, more rarely, headache or nausea. The number of anticholinergic drugs available is increasing. However, uncertainty still exists as to their effectiveness, which ones are best, and which is the optimal route of administration. The relative benefits
Department of Preventive and Social Medicine, University of Otago, PO Box 913, Dunedin, New Zualand

Zealand consulting statistician

Department of Women's and Children's Health, University of Otago

Jean Hay-Smith

Health Research

Council of New

Zealand training

fellow

Gaye Ellis

research assistant

Department of Urogynaecology, St George Hospital,

Kogarah, NSW

2217, Australia

Kate Moore

associate professor of

obstetrics and

gynaecology

Correspondence to:

P Herbison

peter.herbison@

otago.ac.nz

bmj.com 2003;326:841

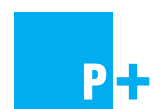

Details of studies and references appear on bmj.com 
of anticholinergics in different patient groups (for example, elderly patients, men compared with women) remains unclear. Despite these uncertainties, anticholinergics are increasingly being used in both primary care and secondary care for the treatment of overactive bladder, and this has considerable implications for resources. ${ }^{8}$

We conducted a systematic review of anticholinergic drug treatment compared with placebo therapy in the treatment of overactive bladder reported in randomised controlled trials.

\section{Methods}

Our study was carried out under the auspices of the Cochrane Incontinence Group. ${ }^{9}$ Relevant trials were identified from the group's specialised register of controlled trials, which is described in the Cochrane Library. ${ }^{10}$ This register is made up from the results of searches of databases and hand searches of relevant conference proceedings. In addition, the cited references from the included trials were searched. The date of the last search was January 2002. We included all randomised controlled trials on men and women with a diagnosis of overactive bladder based on symptoms or a urodynamic diagnosis of detrusor overactivity (either idiopathic or neurogenic), provided one arm of the study used an anticholinergic and another used placebo. Two of the authors independently screened the studies for eligibility. Non-English language papers were translated. Many studies were associated with more than one publication, but we have referenced only the principal publication.

The group of direct antimuscarinic drugs included emepronium bromide, emepronium carrageenate, darifenacin, dicyclomine chloride, oxybutynin chloride, propantheline bromide, propiverine, tolterodine, and trospium chloride. Terodiline was excluded because it has been withdrawn from the market. We also excluded other drugs with less direct anticholinergic effects-for example, smooth muscle relaxants (flavoxate hydrochloride, calcium channel blockers, potassium channel openers, $\beta$ adrenoceptor agonists, $\alpha$ adrenoceptor antagonists, and prostaglandin synthetase inhibitors) and tricyclic antidepressants.

Primary outcomes of interest were patient's observations of cure or improvement in symptoms, number of leakages, and number of voids. Secondary outcomes were urodynamic measures (volume at first contraction, maximum cystometric capacity, residual volume) and adverse events. Quality of life and economic outcomes were also considered. Methodological quality was assessed by considering the adequacy of random allocation and concealment, description of dropouts and withdrawals, analysis by intention to treat, and blinding during treatment and at outcome assessment.

Data were independently abstracted by at least two reviewers and cross checked. Where data were collected but were not reported, or were reported in a form not suitable for inclusion in the formal analysis, further clarification was sought from trialists.

\section{Data analysis}

In trials with two or more active (anticholinergic drug) treatment arms, the data from the active treatments were combined for comparison with placebo. Included trial data were processed as described in the Cochrane Collaboration Handbook using the Metaview 4.1 program. ${ }^{11}$ Data were combined with a fixed effects model using relative risk for dichotomous outcomes and weighted mean differences for continuous outcomes. Some studies reported outcomes at the end of treatment, and some reported changes from baseline. These results are reported separately, but were combined into the pooled overall estimate.

We planned a priori sensitivity analyses to investigate the effects of age, sex, severity of symptoms, cause of overactive bladder symptoms (idiopathic $v$ neurogenic), and type of drug. Data plots were examined for evidence of heterogeneity, and a formal test of heterogeneity was used. Where heterogeneity was observed an explanation was sought. Funnel plots were examined for evidence of small sample bias.

\section{Results}

We identified 64 potential trials. Thirteen reports were excluded: three were analyses of more than one study with no individual study data, ${ }^{\mathrm{w} 1-\mathrm{w} 3}$ five were in elderly patients with no evidence that they had overactive bladders, ${ }^{w 4-w 8}$ in one the placebo arm was not randomised, ${ }^{\mathrm{w} 9}$ two were not comparisons of suitable anticholinergic drugs with placebo, ${ }^{\text {w10 }}{ }^{\text {w11 }}$ and two did not report suitable outcomes. ${ }^{\text {w12 }}{ }^{\text {w13 }}$ We excluded 19 cross over trials as data were presented in a manner that was unsuitable for analysis. ${ }^{12}$ w14w32 The remaining 32 trials were analysed. ${ }^{\text {w33-w64 }}$ Some trials had multiple publications (maximum 13). ${ }^{w 63}$ The 32 trials recruited a total of 6800 participants (1529 men and 3938 women; some trials did not report sex). Of these, 3866 (57\%) participants were randomised to receive anticholinergic drugs and $1743(26 \%)$ were randomised to receive placebo. Three trials did not report the numbers randomised to each group, ${ }^{w 39}$ w40 $w 59$ and three studies only reported the numbers after excluding the dropouts. ${ }^{\mathrm{w} 33} \mathrm{w} 41 \mathrm{w} 48$ Sample sizes ranged from 20 to 1529 , with a median of $155 .^{\text {w54 w63 }}$

Details of the 32 included trials appear on bmj.com. Inclusion and exclusion criteria were unclear for some of the trials. Most trials included people with overactive bladder, regardless of sex, but some were restricted to those with urge urinary incontinence, some to women only, and one to men with bladder outlet obstruction. ${ }^{\text {w35 }}$

Trials compared the following active treatments with

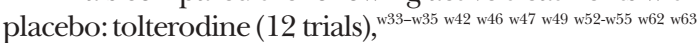
oxybutynin chloride (10 trials), ${ }^{w 34}$ w37 w42-w44 w50 w51 w58 w60 w64 trospium chloride (eight trials), ${ }^{\mathrm{w} 36}$ w38 w39 w44 w48 w49 w46 w61 propiverine (five trials), ${ }^{w 41}$ w45 ${ }^{551} \quad$ w57 $w_{59}$ emepronium bromide (one trial), ${ }^{\mathrm{w} 44}$ and propantheline (one trial). ${ }^{\mathrm{w} 60}$ Six trials compared two different anticholinergics with placebo (tolterodine and oxybutynin, oxybutynin and trospium chloride, tolterodine and trospium chloride, oxybutynin and propiverine, oxybutynin and propan-

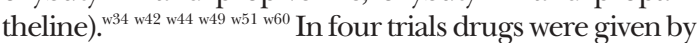
intravesical administration, and in all the remaining trials drugs were taken orally. ${ }^{\mathrm{w} 43} \mathrm{w}^{\mathrm{w} 4} \mathrm{w}^{\mathrm{w} 0}{ }^{\mathrm{w} 54}$ In the trials of oral drugs, length of treatment ranged from 12 days to 12 weeks. ${ }^{\text {w34 w42 w43 w53 w63 }}$ Outcome was measured at the end or shortly after the end of the treatment period in all trials. 
The trials were more explanatory than pragmatic. ${ }^{13}$ Outcome was generally measured at the end of treatment, and there was a focus on urodynamic measures. Due to deficiencies in data reporting (for example, point estimate without measure of variation), many trials contributed limited data to the review.

\section{Methodological quality of included studies}

The method of group allocation was rarely described, although all trials but one were said to be double blind. ${ }^{w 44}$ Although double blinding should adequately conceal group allocation, this is not guaranteed..$^{14}$ Only one trial specifically stated that outcome assessors were blind to group allocation. ${ }^{\text {w37 }}$ In some studies the code was broken on completion of the study, but only a few specified that this was after the analysis.

Baseline comparability of the groups was not mentioned in seven studies. ${ }^{\mathrm{w} 39} \mathrm{w} 44 \mathrm{w} 45 \mathrm{w} 48-\mathrm{w} 50 \mathrm{w} 64$ The remaining 25 trials stated that the groups were comparable at baseline, although three studies did not provide supporting data. ${ }^{\text {w35 }}$ w38 w59 In 13 trials the evaluation of treatment efficacy was conducted on intention to treat principles, ${ }^{\mathrm{w} 34} \mathrm{w} 37 \mathrm{w} 38 \mathrm{w} 44 \mathrm{w} 46 \mathrm{w} 48 \mathrm{w} 51-\mathrm{w} 54 \mathrm{w} 58 \mathrm{w} 63 \mathrm{w} 64$ and seven trials

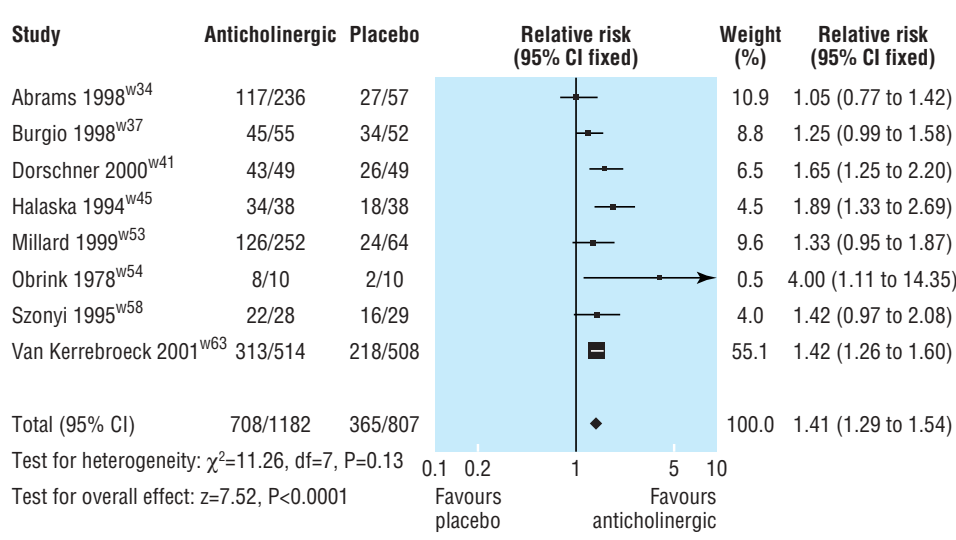

Fig 1 Effect of anticholinergics compared with placebo on patient perception of cure or improvement in symptoms of overactive bladder

specifically stated that a per protocol analysis was used to assess efficacy of treatment. ${ }^{\text {w33 w36 w41 w42 w49 w61 w62 }}$

The description of withdrawals or dropouts was not adequate in eight trials. ${ }^{\text {w3 }}$ w38 w39 w45 w48 w49 w59 w62 No

\begin{tabular}{|c|c|c|c|c|c|c|c|c|}
\hline Study & $\begin{array}{l}\text { Anticholinergic } \\
\text { No of participants }\end{array}$ & Mean (SD) & $\begin{array}{c}\text { Placebo } \\
\text { No of participants }\end{array}$ & Mean (SD) & \multicolumn{2}{|c|}{$\begin{array}{l}\text { Weighted mean difference } \\
(95 \% \mathrm{Cl} \text { fixed })\end{array}$} & $\begin{array}{c}\text { Weight } \\
(\%)\end{array}$ & $\begin{array}{l}\text { Weighted mean difference } \\
\text { (95\% Cl fixed) }\end{array}$ \\
\hline \multicolumn{9}{|c|}{ Leakage episodes in 24 hours } \\
\hline \multicolumn{9}{|c|}{ No of leakage episodes } \\
\hline Burgio $1998^{\mathrm{w} 37}$ & 65 & $0.81(1.40)$ & 62 & $1.20(1.70)$ & -1 & & 9.8 & $-0.39(0.93$ to 0.15$)$ \\
\hline Subtotal $(95 \% \mathrm{Cl})$ & 65 & & 62 & & 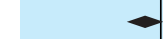 & & 9.8 & $-0.39(0.93$ to 0.15$)$ \\
\hline \multicolumn{9}{|c|}{ Test for heterogeneity: $\chi^{2}=0.00, d f=0, P=1.00$} \\
\hline \multicolumn{9}{|c|}{ Test for overall effect: $z=1.41, P=0.16$} \\
\hline \multicolumn{9}{|l|}{ Change in leakage episodes } \\
\hline Abrams $1998^{\mathrm{w} 34}$ & 180 & $-1.50(3.20)$ & 40 & $-0.90(1.50)$ & $\cdots$ & & 6.7 & $-0.60(-1.26$ to 0.06$)$ \\
\hline Dorschner $2000^{w 41}$ & 49 & $-0.60(1.70)$ & 49 & $-0.10(0.70)$ & $\longrightarrow$ & & 10.9 & $-0.50(-1.01$ to 0.01$)$ \\
\hline Drutz $1999^{w 42}$ & 99 & $-1.70(1.90)$ & 33 & $-1.00(2.20)$ & - & & 4.1 & $-0.70(-1.54$ to 0.14$)$ \\
\hline Jacquetin $2001^{w 46}$ & 157 & $-1.20(2.00)$ & 39 & $-0.40(1.90)$ & - & & 6.4 & $-0.80(-1.47$ to -0.13$)$ \\
\hline Millard 1999w53 & 226 & $-1.70(2.70)$ & 55 & $-1.30(2.50)$ & - & & 5.2 & $-0.40(-1.15$ to 0.35$)$ \\
\hline Rentzhog $1998^{\text {w55 }}$ & 54 & $-0.98(1.47)$ & 10 & $-0.40(0.80)$ & $\longrightarrow$ & & 7.2 & $-0.58(-1.21$ to 0.05$)$ \\
\hline Van Kerrebroeck $1998^{\text {w62 }}$ & 60 & $-1.59(3.10)$ & 16 & $-1.90(2.20)$ & - & & 1.6 & $0.31(-1.02$ to 1.64$)$ \\
\hline Van Kerrebroeck $2001^{\text {w63 }}$ & 1021 & $-1.60(2.50)$ & 507 & $-0.99(2.20)$ & $=$ & & 48.1 & $-0.61(-0.86$ to -0.36$)$ \\
\hline Subtotal $(95 \% \mathrm{Cl})$ & 1846 & & 749 & & $\bullet$ & & 90.2 & $-0.58(-0.76$ to -0.40$)$ \\
\hline \multicolumn{9}{|c|}{ Test for heterogeneity: $\chi^{2}=2.58, d f=7, P=0.92$} \\
\hline \multicolumn{9}{|c|}{ Test for overall effect: $z=6.37, P<0.0001$} \\
\hline Total $(95 \% \mathrm{Cl})$ & 1911 & & 811 & & $\bullet$ & & 100.0 & $-0.56(0.93$ to 0.15$)$ \\
\hline \multicolumn{9}{|c|}{ Test for heterogeneity: $\chi^{2}=3.01, d f=8, P=0.93$} \\
\hline \multicolumn{9}{|c|}{ Test for overall effect: $z=6.49, P<0.0001$} \\
\hline \multicolumn{9}{|l|}{ Micturitions in 24 hours } \\
\hline Abrams $1998^{\text {w34 }}$ & 235 & $-2.50(3.30)$ & 56 & $-1.60(3.60)$ & & & 5.1 & $-0.90(-1.93$ to 0.13$)$ \\
\hline Dorschner $2000^{w 41}$ & 49 & $-2.10(3.10)$ & 49 & $-0.60(2.50)$ & - & & 4.4 & $-1.50(-2.62$ to -0.38$)$ \\
\hline Drutz 1999 & 111 & $-2.00(2.40)$ & 36 & $-1.10(2.90)$ & & & 5.0 & $-0.90(-1.95$ to 0.15$)$ \\
\hline Jacquetin $2001^{\text {w46 }}$ & 157 & $-1.40(3.60)$ & 39 & $-1.20(2.70)$ & & - & 5.3 & $-0.20(-1.22$ to 0.82$)$ \\
\hline Millard 1999w53 & 252 & $-2.30(2.60)$ & 64 & $-1.40(2.30)$ & - & & 12.9 & $-0.90(-1.55$ to -0.25$)$ \\
\hline Rentzhog $1998^{w 55}$ & 54 & $-1.80(2.50)$ & 10 & $-0.30(1.40)$ & - & & 4.5 & $-1.50(-2.59$ to -0.41$)$ \\
\hline Van Kerrebroeck $1998^{\text {w62 }}$ & 60 & $-0.01(1.80)$ & 16 & $-0.10(1.00)$ & - & - & 12.1 & $0.09(-0.58$ to 0.76$)$ \\
\hline Van Kerrebroeck $2001^{\text {w63 }}$ & 1021 & $-1.70(3.40)$ & 507 & $-1.20(2.90)$ & $=$ & & 50.7 & $-0.50(-0.83$ to -0.17$)$ \\
\hline Subtotal $(95 \% \mathrm{Cl})$ & 1939 & & 777 & & $\bullet$ & & 100.0 & $-0.59(-0.83$ to -0.36$)$ \\
\hline \multicolumn{5}{|c|}{ Test for heterogeneity: $\chi^{2}=11.60, d f=7, P=0.11$} & $-4 \quad-2$ & 2 & & \\
\hline \multicolumn{5}{|c|}{ Test for overall effect: $z=4.99, P<0.0001$} & $\begin{array}{l}\text { Favours } \\
\text { anticholinergic }\end{array}$ & $\begin{array}{l}\text { Favour } \\
\text { placeb }\end{array}$ & & \\
\hline
\end{tabular}

Fig 2 Effect of anticholinergics compared with placebo on number of leakages in 24 hours and number of micturitions in 24 hours 


\begin{tabular}{|c|c|c|c|c|c|c|c|c|}
\hline Study & $\begin{array}{l}\text { Anticholinergic } \\
\text { No of participants }\end{array}$ & Mean (SD) & $\begin{array}{c}\text { Placebo } \\
\text { No of participants }\end{array}$ & ts Mean (SD) & \multicolumn{2}{|c|}{$\begin{array}{l}\text { Weighted mean difference } \\
(95 \% \text { CI fixed })\end{array}$} & $\begin{array}{l}\text { Weight } \\
(\%)\end{array}$ & $\begin{array}{l}\text { Weighted mean difference } \\
\text { (95\% Cl fixed) }\end{array}$ \\
\hline \multicolumn{9}{|c|}{ Maximum cystometric capacity } \\
\hline \multicolumn{9}{|c|}{ Maximum cystometric capacity } \\
\hline Cardozo 2000"w38 & 104 & $356.20(182.10)$ & 103 & $335.60(164.70)$ & & & 5.7 & $20.60(-26.69$ to 67.89$)$ \\
\hline Stohrer $1999^{w 57}$ & 52 & $366.00(143.00)$ & 50 & $289.00(163.00)$ & & & 3.6 & $77.00(17.40$ to 136.60$)$ \\
\hline Subtotal $(95 \% \mathrm{Cl})$ & 156 & & 153 & & & & 9.3 & 42.39 (5.35 to 79.44$)$ \\
\hline \multicolumn{9}{|c|}{ Test for heterogeneity: $\chi^{2}=2.11, \mathrm{df}=1, \mathrm{P}=0.15$} \\
\hline \multicolumn{9}{|c|}{ Test for overall effect: $z=2.24, P=0.02$} \\
\hline \multicolumn{9}{|c|}{ Change in maximum cystometric capacity } \\
\hline Abrams $1998^{\text {w33 }}$ & 52 & $72.00(125.00)$ & 15 & $7.00(5.00)$ & & & 11.0 & 65.00 (30.93 to 99.07 ) \\
\hline Alloussi $1998^{\mathrm{w} 36}$ & 99 & $79.10(103.10)$ & 48 & $5.20(99.20)$ & & & 10.7 & $73.90(39.26$ to 108.54$)$ \\
\hline Froehlich 1998'w4 & 42 & $125.40(115.10)$ & 21 & $-9.10(69.94)$ & & $\rightarrow$ & 6.1 & 134.50 (88.60 to 180.40$)$ \\
\hline Jonas $1997^{\mathrm{w} 47}$ & 197 & $31.00(117.00)$ & 44 & $4.00(104.00)$ & & & 10.6 & $27.00(-7.80$ to 61.80$)$ \\
\hline Junemann 1999 w48 & 112 & $78.05(84.87)$ & 58 & $24.71(89.91)$ & & & 16.3 & 53.34 (25.37 to 81.31$)$ \\
\hline Madersbacher 199gw51 & 247 & $92.00(107.00)$ & 63 & $52.00(92.00)$ & & - & 18.4 & 40.00 (13.65 to 66.35$)$ \\
\hline Rentzhog $1998^{\mathrm{w} 55}$ & 54 & $27.30(130.00)$ & 10 & $-17.00(125.00)$ & & & 1.8 & $44.30(-40.58$ to 129.18$)$ \\
\hline Thuroff 1991w60 & 117 & $65.70(121.40)$ & 52 & $22.50(116.10)$ & & & 8.6 & $43.20(4.73$ to 81.67$)$ \\
\hline Ulshofer 2001 ${ }^{\text {w61 }}$ & 22 & $82.30(101.85)$ & 17 & $-4.10(100.30)$ & & & 3.1 & 86.40 (22.49 to 150.31$)$ \\
\hline Van Kerrebroeck $1998^{\text {w62 }}$ & 60 & $68.00(133.00)$ & 16 & $43.00(92.00)$ & & & 4.0 & $25.00(-31.26$ to 81.26$)$ \\
\hline Subtotal $(95 \% \mathrm{Cl})$ & 1002 & & 344 & & & - & 90.7 & 55.57 (43.69 to 67.44$)$ \\
\hline \multicolumn{9}{|c|}{ Test for heterogeneity: $\chi^{2}=19.18, d f=9, P=0.024$} \\
\hline \multicolumn{9}{|c|}{ Test for overall effect: $z=9.17, P<0.0001$} \\
\hline Total $(95 \% \mathrm{Cl})$ & 1158 & & 497 & & & - & 100.0 & 54.34 (43.03 to 65.65$)$ \\
\hline \multicolumn{9}{|c|}{ Test for heterogeneity: $\chi^{2}=21.73, \mathrm{df}=11, \mathrm{P}=0.027$} \\
\hline \multicolumn{9}{|c|}{ Test for overall effect: $z=9.42, P<0.0001$} \\
\hline \multicolumn{9}{|l|}{ Volume at first contraction } \\
\hline \multicolumn{9}{|l|}{ Volume at first contraction } \\
\hline Cardozo 2000"w38 & 102 & $298.60(194.80)$ & 103 & $255.70(177.30)$ & & & 8.4 & $42.90(-8.11$ to 93.91$)$ \\
\hline Stohrer $1999^{\mathrm{w} 57}$ & 52 & $224.00(111.00)$ & 50 & $159.00(107.00)$ & & & 12.2 & 65.00 (22.69 to 107.31$)$ \\
\hline Subtotal $(95 \% \mathrm{Cl})$ & 154 & & 153 & & & & 20.7 & 55.99 (23.43 to 88.56) \\
\hline \multicolumn{9}{|c|}{ Test for heterogeneity: $\chi^{2}=0.43, d f=1, P=0.51$} \\
\hline \multicolumn{9}{|c|}{ Test for overall effect: $z=3.37, P=0.0008$} \\
\hline \multicolumn{9}{|c|}{ Change in volume at first contraction } \\
\hline Abrams $1998^{\text {w33 }}$ & 52 & $62.00(119.00)$ & 15 & $14.00(42.00)$ & & & 14.6 & 48.00 (9.30 to 86.70$)$ \\
\hline Alloussi $1998^{\text {w36 }}$ & 98 & $97.70(123.50)$ & 48 & $42.70(89.90)$ & & & 17.6 & 55.00 (19.72 to 90.28$)$ \\
\hline Jonas $1997^{\text {w47 }}$ & 197 & $78.00(144.00)$ & 44 & $40.00(134.00)$ & & & 11.1 & $38.00(-6.41$ to 82.41$)$ \\
\hline Junemann $1999^{\text {w48 }}$ & 112 & $124.54(143.60)$ & 58 & $60.21(123.28)$ & & & 12.8 & 64.33 (22.93 to 105.73$)$ \\
\hline Rentzhog $1998^{w 55}$ & 54 & $69.60(142.40)$ & 10 & $-23.00(103.00)$ & & & 4.0 & 92.60 (18.32 to 166.88 ) \\
\hline Thuroff 1991w60 & 117 & $32.60(162.70)$ & 52 & $-9.70(128.40)$ & & & 10.5 & $42.30(-3.39$ to 87.99$)$ \\
\hline Van Kerrebroeck $1998^{\text {w62 }}$ & 60 & $79.00(116.00)$ & 16 & $40.00(83.00)$ & & & 8.7 & $39.00(-11.16$ to 89.16$)$ \\
\hline Subtotal $(95 \% \mathrm{Cl})$ & 690 & & 243 & & & 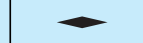 & 79.3 & 51.28 (34.65 to 67.90$)$ \\
\hline \multicolumn{9}{|c|}{ Test for heterogeneity: $\chi^{2}=2.36, d f=6, P=0.88$} \\
\hline \multicolumn{9}{|c|}{ Test for overall effect: $z=6.05, P<0.0001$} \\
\hline Total $(95 \% \mathrm{Cl})$ & 844 & & 396 & & & $<$ & 100 & 52.25 (37.45 to 67.06$)$ \\
\hline \multicolumn{5}{|c|}{ Test for heterogeneity: $\chi^{2}=2.85, \mathrm{df}=8, \mathrm{P}=0.94$} & & & & \\
\hline Test for overall effect: $z=6$ & $92, P<0.0001$ & & & & $\begin{array}{l}\text { Favours } \\
\text { placebo }\end{array}$ & $\begin{array}{r}\text { Favour } \\
\text { anticholinergi }\end{array}$ & & \\
\hline
\end{tabular}

Fig 3 Effect of anticholinergics compared with placebo on maximum cystometric capacity and bladder volume at first contraction

dropouts occurred in the trials using single intravesical or oral doses of drug, ${ }^{w 43}{ }^{w 44} w_{50} w^{54} w_{64}$ and in nine trials the dropout rate was $10 \%$ or less. ${ }^{\text {w41 }}$ w46 w47 w50 w52 w53 w56 w57 w60 In the remainder, dropout rates ranged from $12 \%$ to $21 \%$. ${ }^{\text {w42 } w 43 \text { w5 } 1 \text { w5 w63 }}$

The primary, or only, reference for seven of the 32 included trials was a conference abstract, and none of these were interim reports of continuing studies. $^{\text {w33, w35 }}$ w39 w48-w50 w59 Eight trials reported the patient's perception of cure or improvement in symptoms (fig 1).w34 w37 w41 w45 w53 w54 w58 w63 Those receiving active treatment were more likely to be subjectively improved (relative risk 1.41, 95\% confidence interval 1.29 to 1.54). Nine trials reported on post-treatment leakage

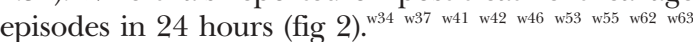
Those taking an anticholinergic had about one leakage episode less in 48 hours than those taking placebo (estimated mean difference for reduction in number of 


\begin{tabular}{|c|c|c|c|c|c|c|c|c|c|}
\hline Study & $\begin{array}{l}\text { Anticholinergic } \\
\text { No of participants }\end{array}$ & Mean (SD) $\mathrm{N}$ & $\begin{array}{l}\text { Placebo } \\
\text { No of participants }\end{array}$ & Mean (SD) & \multicolumn{3}{|c|}{$\begin{array}{l}\text { Weighted mean difference } \\
\quad(95 \% \text { Cl fixed) }\end{array}$} & $\begin{array}{l}\text { Weight } \\
(\%)\end{array}$ & $\begin{array}{l}\text { Weighted mean difference } \\
(95 \% \mathrm{Cl} \text { fixed })\end{array}$ \\
\hline \multicolumn{10}{|l|}{ Residual volume } \\
\hline Cardozo $2000^{\text {w38 }}$ & 102 & $25.00(39.10)$ & 101 & $22.20(44.70)$ & & $t$ & & 8.3 & $2.80(-8.76$ to 14.36$)$ \\
\hline Dorschner $2000^{w 41}$ & 49 & $7.20(12.40)$ & 49 & $5.90(8.00)$ & & 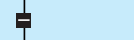 & & 65.1 & $1.30(-2.83$ to 5.43$)$ \\
\hline Stohrer 1999w57 & 52 & $86.50(109.30)$ & 50 & $60.80(71.90)$ & & & & 0.9 & $25.70(-10.07$ to 61.47$)$ \\
\hline Subtotal $(95 \% \mathrm{Cl})$ & 203 & & 200 & & & 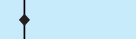 & & 74.3 & 1.75 (-2.11 to 5.62$)$ \\
\hline \multicolumn{10}{|c|}{ Test for heterogeneity: $\chi^{2}=1.80, \mathrm{df}=2, \mathrm{P}=0.41$} \\
\hline \multicolumn{10}{|c|}{ Test for overall effect: $z=0.89, P=0.4$} \\
\hline \multicolumn{10}{|l|}{ Change in residual volume } \\
\hline Abrams $1998^{\mathrm{w} 33}$ & 52 & $47.00(148.00)$ & 15 & $-1.00(40.00)$ & & & & 0.5 & 48.00 (2.97 to 93.03$)$ \\
\hline Alloussi 1998w36 & 98 & $1.60(53.30)$ & 45 & $2.40(14.10)$ & & - & & 8.7 & $-0.80(-12.13$ to 10.53$)$ \\
\hline Froehlich $1998^{\text {w44 }}$ & 42 & $109.40(139.10)$ & 21 & $-24.50(60.31)$ & & & $\rightarrow$ & 0.5 & $133.90(84.55$ to 183.25$)$ \\
\hline Jonas $1997^{\text {w47 }}$ & 197 & $14.00(55.00)$ & 44 & $3.00(54.00)$ & & 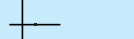 & & 3.5 & 11.00 (-6.71 to 28.71$)$ \\
\hline Junemann $1999^{\text {w48 }}$ & 112 & $15.29(42.93)$ & 58 & $9.41(50.37)$ & & - & & 4.8 & $5.88(-9.33$ to 21.09$)$ \\
\hline Rentzhog $1998^{\text {w55 }}$ & 54 & $39.90(103.10)$ & 10 & $4.00(49.00)$ & & & & 0.7 & $35.90(-5.07$ to 76.87$)$ \\
\hline Thuroff $1991^{\text {w60 }}$ & 117 & $13.50(68.40)$ & 52 & $-1.90(11.50)$ & & $\rightarrow$ & & 6.8 & $15.40(2.62$ to 28.18$)$ \\
\hline Van Kerrebroeck $1998^{\text {w62 }}$ & 45 & $81.00(116.00)$ & 12 & $83.00(108.00)$ & & & & 0.2 & $-2.00(-71.88$ to 67.88$)$ \\
\hline Subtotal $(95 \% \mathrm{Cl})$ & 717 & & 257 & & & $\bullet$ & & 25.7 & $10.73(4.15$ to 17.30$)$ \\
\hline \multicolumn{10}{|c|}{ Test for heterogeneity: $\chi^{2}=33.03, \mathrm{df}=7, \mathrm{P}<0.0001$} \\
\hline \multicolumn{10}{|c|}{ Test for overall effect: $z=3.20, P=0.001$} \\
\hline Total $(95 \% \mathrm{Cl})$ & 920 & & 457 & & & - & & 100.0 & 4.06 (0.73 to 7.39$)$ \\
\hline \multicolumn{5}{|c|}{ Test for heterogeneity: $\chi^{2}=40.14, \mathrm{df}=10, \mathrm{P}<0.0001$} & $-100 \quad-50$ & 50 & 100 & & \\
\hline \multicolumn{5}{|c|}{ Test for overall effect: $z=2.39, P=0.02$} & $\begin{array}{l}\text { Favours } \\
\text { anticholinergic }\end{array}$ & $\begin{array}{l}\text { Favo } \\
\text { place }\end{array}$ & $\begin{array}{l}\text { lou } \\
\text { ours } \\
\text { sebo }\end{array}$ & & \\
\hline
\end{tabular}

Fig 4 Effect of anticholinergics compared with placebo on residual urinary volume

leakage episodes in 24 hours 0.6, 0.4 to 0.8 ). Eight trials reported on the number of micturitions in 24 hours

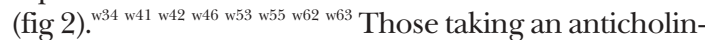
ergic had about one less micturition in 48 hours than those taking placebo (estimated mean difference for reduction number of micturitions in 24 hours $0.6,0.4$ to 0.8 ). No significant heterogeneity was found in these results.

Twelve trials reported either maximum cystometric capacity after treatment or change in maximum cystometric capacity after treatment (fig 3). ${ }^{\mathrm{w} 33-w 38}$ w44-w57 w60-w62 A larger increase in maximum cystometric capacity occurred in those receiving active treatment (estimated mean difference $54 \mathrm{ml}, 43 \mathrm{ml}$ to $66 \mathrm{ml}$ ). Significant heterogeneity was observed $(\mathrm{P}=0.027)$. When the data from Froehlich et al, in which participants received treatment by intravesical administration, was removed from the pooled analysis, there was an improvement in maximum cystometric capacity in favour of the drug group ( $49 \mathrm{ml}, 38 \mathrm{ml}$ to $61 \mathrm{ml}$ ), and the test for heterogeneity was no longer significant $(\mathrm{P}=0.51){ }^{\mathrm{w} 44}$

Nine trials reported either volume at first contraction after treatment or change in volume at first

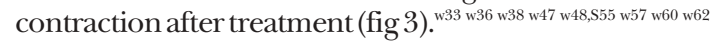
Volume at first contraction increased more in the drug group than in the placebo group $(52 \mathrm{ml}, 38 \mathrm{ml}$ to 67 $\mathrm{ml})$.

Residual volume after treatment or change in residual volume after treatment was reported by 11 trials (fig 4). ${ }^{\text {333,536 w38 w44 w47 w48 w51 w55 w57 w60 w62 }}$ On average, residual volume was $4 \mathrm{ml}$ greater in the drug group (4 $\mathrm{ml}, 1 \mathrm{ml}$ to $7 \mathrm{ml}$ ), but significant heterogeneity was observed $(\mathrm{P}<0.0001)$. When the data from Froehlich et al were excluded from the pooled analysis, those receiving active treatment had an increase in residual volume compared with those receiving placebo $(3.5 \mathrm{ml}$, $0.1 \mathrm{ml}$ to $6.8 \mathrm{ml}$ ), and the test for heterogeneity was no longer significant $(\mathrm{P}=0.14)$. $^{\mathrm{w} 6}$

Thirteen trials reported the number of people withdrawing owing to adverse events (fig 5). ${ }^{\text {w34-w36 w42 w46 w47 w51-w63 }}$ No significant difference was found in the number of withdrawals due to adverse events between drug and placebo groups (relative risk 1.01, 0.78 to 1.31), but there was significant heterogeneity $(\mathrm{P}=0.08)$. Excluding the data from Rentzhog et al, a dose ranging study of tolterodine, did not change the finding of the pooled analysis very much $(1.05,0.81$ to 1.38$)$, but the test for heterogeneity was no longer significant $(\mathrm{P}=0.24) .{ }^{\mathrm{w5} 5}$

Dry mouth was the most frequently reported side effect, and data on this were available from 20 trials

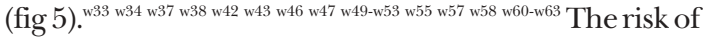
dry mouth was two and a half times greater in the drug group (relative risk 2.56, 2.24 to 2.92). Significant heterogeneity was observed in this comparison $(\mathrm{P}<0.0001)$. Two trials, in elderly patients, had high rates of dry mouth in the placebo arm, perhaps as a consequence of polypharmacy. ${ }^{\mathrm{w} 37}{ }^{\mathrm{w} 58}$ When these two trials were excluded from the pooled analysis, the risk of dry mouth was nearly three times greater $(2.88,2.46$ to 3.36), and the test of heterogeneity was no longer significant $(\mathrm{P}=0.11)$.

Despite clinical heterogeneity of the included trials (for example, sample populations and type of drug), sensitivity analyses did not show any differences in the results for age, sex, diagnosis (neurogenic or idiopathic detrusor overactivity), or type of drug. Changing to a random effects model to get the pooled estimate did not change the results much or change the interpretation. The quality of the trials was uniform in the elements that have been shown to be most related 


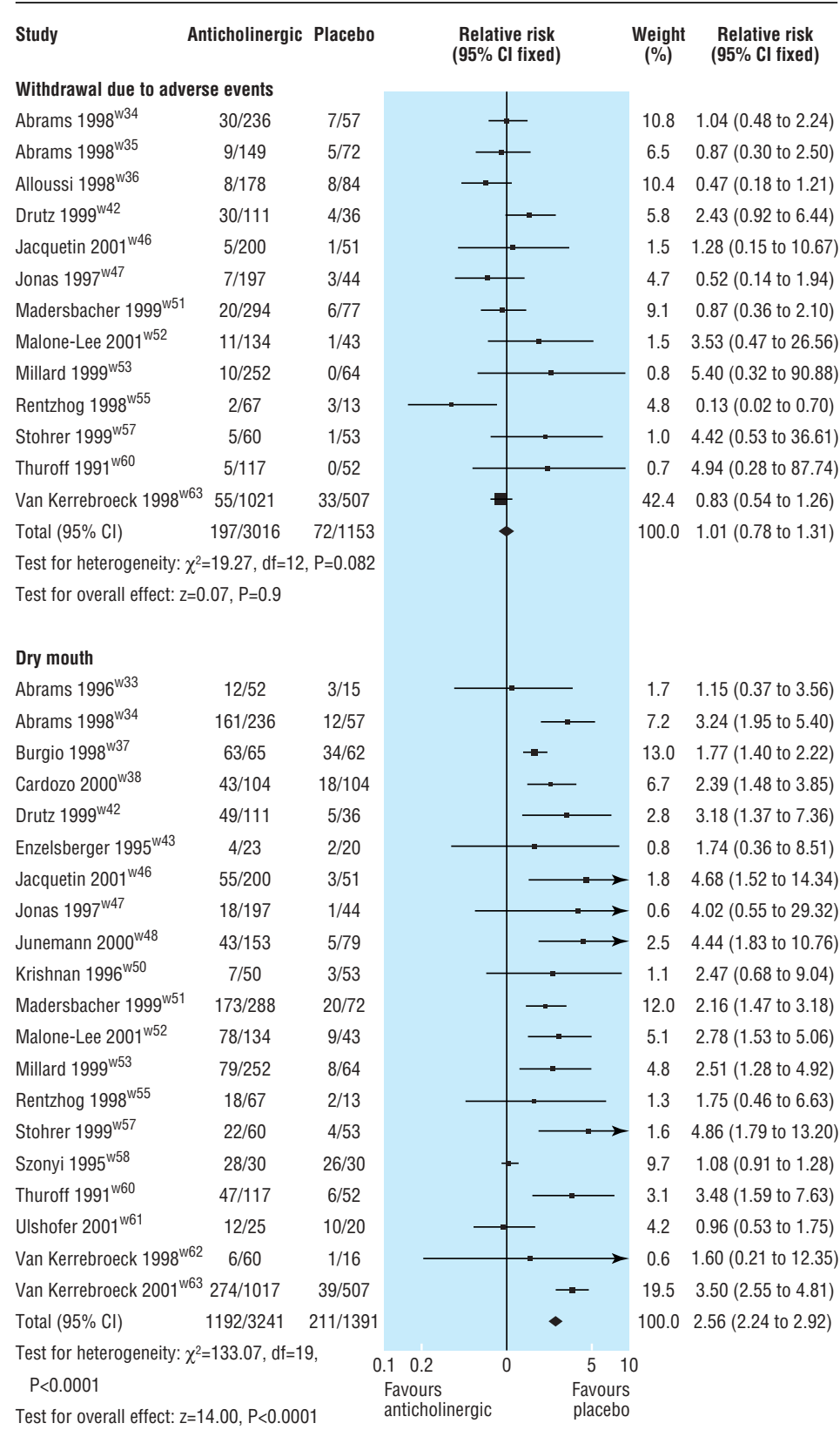

Fig 5 Effect of anticholinergics compared with placebo on withdrawal owing to side effects and dry mouth tinence in the $1980 \mathrm{~s}$, these were seldom employed. The effect of repeated completion of bladder diaries could not be ascertained, but may have had a bladder retraining effect in both groups.

Many of the included studies did not report outcomes that were used in this systematic review, even though these are recommended by of the International Continence Society. ${ }^{15}$ In addition many results were reported in a manner that rendered them unsuitable for combination with others-for example, no measure of variation was given. These omissions could have created bias, but the lack of heterogeneity would suggest that this is unlikely.

New drugs are currently being developed for the treatment of overactive bladder, as are new formulations (for example, extended release forms) and new routes of administration, such as the skin patch. These may have larger effects or have fewer side effects than is currently the case, but such possible benefits cannot be judged from our systematic review.

The included studies were explanatory rather than pragmatic, with limited follow up and a focus on surrogate outcomes. Because of this, and the small differences shown, the clinical relevance of the differences we found is uncertain. However, it is clear that anticholinergics have positive effects. Therefore we believe that the use of placebo arms in trials with anticholinergic drugs for the treatment of overactive bladder should be restricted to short term explanatory studies for the purpose of facilitating the licensing of new drugs in this class.

Two small trials that compared intravesical administration of anticholinergic or placebo did seem to have more pronounced effects than trials using oral administration. Rates of cure or improvement in symptoms seemed to be increased, there was a greater increase in maximum cystometric capacity but also a greater increase in residual urine after anticholinergic therapy. These differences might be due to chance, the difference in route of administration, or some difference in the study populations. ${ }^{\mathrm{w} 44} \mathrm{w}^{\mathrm{w} 4}$

Many studies showed that trials sponsored by drug companies have more favourable outcomes than those with independent funding. ${ }^{16}{ }^{17}$ Twelve of the 32 trials declared the support of a pharmaceutical company. ${ }^{\mathrm{w} 34} \mathrm{w} 38 \mathrm{w} 40-\mathrm{w} 42 \mathrm{w} 46 \mathrm{w} 55 \mathrm{w} 58 \mathrm{w} 60-\mathrm{w} 63$ This support ranged from the supply of active and placebo tablets through to full funding and data analysis. None of the remaining trials made any statement about the absence or presence of company involvement, except that one trial was funded by a grant from a health research body. ${ }^{\text {w37 }}$

The observed difference in treatment effect between active drug and placebo was of lesser magnitude than expected from clinical experience. Many people treated for overactive bladder receive anticholinergic drugs and instruction in bladder retraining simultaneously. In contrast, most of the studies cited here did not provide any formal bladder retraining, and in many trials people who had undergone bladder retraining were excluded.

To date there has been no pragmatic comparison of anticholinergic drugs with bladder retraining, the main alternative conservative management of overactive bladder syndrome. A Cochrane systematic review shows that the effects of bladder retraining compared this was true for the placebo groups as well as for the treated groups. Despite the emergence of numerous disease specific quality of life tests pertaining to incon- 


\section{What is already known on this topic}

Anticholinergics are the first line medical treatment for overactive bladder

The effectiveness of these drugs is unclear

\section{What this study adds}

Anticholinergics produce significant improvements in overactive bladder symptoms compared with placebo

The benefits are, however, of limited clinical significance

with placebo may be similar to the differences found here. ${ }^{18} \mathrm{~A}$ comparison of these two treatments, and their effectiveness when combined, should be undertaken.

We thank Birgit Moehrer for help with assessment of trials published in German, Italian, and Flemish, Fernanda Teixeira for help with trials published in Spanish, and Lief Rentzhog and Wolfgang Dorschner for providing unpublished data.

Contributors: $\mathrm{PH}$ and JH-S designed the review, checked the inclusion of studies and the data extraction, and wrote the first draft of the paper. GE tracked down the studies, extracted the data, and helped with the editing of the paper. KM ensured that the questions and conclusions were valid and helped with the editing of the paper. $\mathrm{PH}$ and JH-S will act as guarantors for the paper.

Funding: JH-S was funded by the Health Research Council of New Zealand. GE was partly funded by an internal research grant from the University of Otago.

Competing interests: GE was the study coordinator for one of the centres in a multicentre and multinational trial included in the review. KM is a coauthor of one included study and the primary author of a cross over study that was excluded from the review, has been reimbursed by two pharmaceutical companies for speaking at symposiums, and has been reimbursed for staff costs and consulting costs.
1 Milsom I, Abrams P, Cardozo L, Roberts RG, Thuroff J, Wein AJ. How widespread are the symptoms of an overactive bladder and how are they managed? A population-based prevalence study. Br J Urol Int managed? A population-based prevalence study. $\mathrm{Br} J$ Urol Int

2 Stewart WF, Corey R, Herzog AR, Wein A, Norton PA, Payne C, et al. Prevalence of overactive bladder in women: results from the Noble Program. Int Urogynecol J Pelvic Floor Dysfunct 2001;12:S66.

3 Brown JS, Grady D, Ouslander JG, Herzog AR, Varner RE, Posner SF. Prevalence of urinary incontinence and associated risk factors in postmenopausal women. Heart and Estrogen/Progestin Replacement Study (HERS) Research Group. Obstet Gynecol 1999;94:66-70.

4 Moller LA, Lose G, Jorgensen T. The prevalence and bothersomeness of lower urinary tract symptoms in women 40-60 years of age. Acta Obstet Gynecol Scand 2000;79:298-305.

5 Ueda T, Tamaki M, Kageyama S, Yoshimura N, Yoshida O. Urinary incontinence among community-dwelling people aged 40 years or older in Japan: prevalence, risk factors, knowledge and self-perception. Int J Urol 2000;7:95-103.

6 Hennessey A, Robertson NP, Swingler R, Compston DA. Urinary, faecal and sexual dysfunction in patients with multiple sclerosis. J Neurol 1999;246:1027-32.

7 Jackson $\mathrm{S}$. The patient with an overactive bladder-symptoms and quality of life issues. Urology 1997;50(suppl 6A):18-22.

8 Kobelt G. Economic considerations and outcome measurement in urge incontinence. Urology 1997;50(suppl 6A):100-7.

9 Hay-Smith J, Herbison P, Ellis G, Moore K. Anticholinergic drugs versus placebo for overactive bladder syndrome in adults. In: Cochrane Library. Issue 3. Oxford: Update Software, 2002

10 Grant AM, Cody DJ, Glazener CMA, Hay-Smith J, Herbison P, Lapitan M, et al. Cochrane Incontinence Group. In: Cochrane Library. Issue 2. Oxford: Update Software, 2002.

11 Clarke M, Oxman AD. Cochrane reviewer's handbook 2000;4.1. [Updated Jun 2000.]

12 Elbourne DR, Altman DG, Higgins JPT, Curtin F, Worthington HV, Vail A. Meta-analysis involving cross-over trials: methodological issues. Int J Epidemiol 2002;31:140-9.

13 Roland M, Torgerson DJ. Understanding controlled trials. What are pragmatic trials? BMJ 1998;316:285.

14 DuBeau CE, Miller KL, Bergmann M, Resnick NM. Urge incontinence outcomes in RCTs depend on assumed and not actual drug assignment.
outinence Neurourol Urodyn 2000;19:492.

15 Mattiasson A, Djurhuus JC, Fonda D, Lose G, Nordling J, Stohrer M. Standardization of outcome studies in patients with lower urinary tract dysfunction: a report on general principles from the Standardisation Committee of the International Continence Society. Neurourol Urodyn 1998; 17:249-53.

16 Smith R. Beyond conflict of interest: transparency is the key. BMJ 1998;317:291-2.

17 Yaphe J, Edman R, Knishkowy B, Herman J. The association between funding by commercial interests and study outcome in randomized controlled drug trials. Fam Pract 2001:18:565-8.

18 Roe B, Williams K, Palmer M. Bladder training for urinary incontinence in adults. In: Cochrane Library. Issue 2. Oxford: Update Software, 2002. (Accepted 20 February 2003) 